\title{
HUBUNGAN ANTARA KOMPETENSI MANAJERIAL KEPALA SEKOLAH DAN KEMAMPUANNYA DALAM APLIKASI TEKNOLOGI INFORMASI DAN KOMUNIKASI DENGAN MUTU PENGELOLAAN SMA NEGERI 21 MAKASSAR
}

\author{
Kurniati \\ Universitas Islam Negeri Alauddin Makassar \\ Jl. HM. Yasin Limpo No. 36 Makassar \\ Email: Kurniaamalia23@gmail.com
}

\begin{abstract}
Abstrak:
This study aims to determine how big the relationship between the principal managerial competence and ability in the application of information and communication technology with the quality of management at SMA Negeri 21 Makassar. This research is a quantitative research with the population in this study are teachers, staff, librarians and students of SMA Negeri 21 Makassar. The sample in this research is 40 teachers, 5 staffs and 40 students. The research data is analyzed by descriptive technique and inferential technique. The result of descriptive analysis of principal managerial competence shows that the average score is 30.63 from the table of descriptive statistical analysis, the average score of ability in the application of information and communication technology is 6 of the statistical test results and the average score of management quality variable is 14.30 from the results of descriptive statistics. The result of inferential analysis is obtained that the principal managerial competence score get the sig value. ( $p$-value) of $0.648>0.05$, meaning that the variable variable The Principal Managerial Capability comes from a normally distributed population. Result of score of ability variable in application of information and communication technology, obtained by sig value. ( $p$-value) of $0.082>0.05$, then $\mathrm{HO}$ is accepted. It means that sample of ICT Application Ability variable comes from normal distributed population. And variable of management quality obtained by result of sig value. ( $p$-value) of $0.685>0.05$, then $\mathrm{HO}$ is accepted. This means that the sample of Quality Quality of School Management comes from the normal distributed population. Pearson correlation analysis results obtained that the correlation between the principal managerial competence with management quality obtained coefficient value of 0.187 with a positive direction. Because the coefficient is close to 0 , it can be concluded that the managerial competence of the principal with the quality of management has a low relationship. coefficient of 0.187 with positive direction. The correlation between ICT application and management quality is 0.627 . Because the coefficient is close to 1 , it can be concluded that the relationship between its ability in ICT applications with the quality of management has a high relationship. So it can be concluded that there is a significant relationship between the principal managerial competence and ability in the application of information and communication technology with the quality management of SMA Negeri 21 Makassar.
\end{abstract}

Kata kunci: Principal Managerial Competencies, ICT Applications, and Quality Management. 


\section{PENDAHULUAN}

paya peningkatan mutu pengelolaan pendidikan melalui pendekatan
pemberdayaan sekolah dalam mengelola sekolahnya telah lama dilakukan.
Berbagai kenyataan rendahnya mutu sekolah dipengaruhi berbagai faktor, salah satunya adalah manajemen pendidikan. Menurut kacamata pemerintah, sekolah yang bermutu harus memenuhi standar nasional pendidikan (SNP), Salah satu cara yang harus dilaksanakan adalah peningkatan mutu pendidikan yang dilandasi dengan kegiatan penjaminan mutu yang dapat dipercaya. Beberapa kondisi yang harus dipenuhi oleh sekolah dalam menerapkan penjaminan mutu pendidikan sebagai berikut, yaitu: melakukan perubahan mind set dalam melayani pendidikan, menerapkan perubahan paradigma dalam manajemen sekolah /madrasah, memastikan setiap komponen dalam pendidikan berfungsi melaksanakan pembelajaran yang bermutu, implementasi sistem penjaminan mutu secara terpadu, konsisten, dan berkelanjutan. ${ }^{1}$

Manajemen mutu sekolah dapat dinyatakan sebagai cara mengelola seluruh sumber daya sekolah, dengan mengarahkan semua orang yang terlibat didalamnya untuk melaksanakan tugas sesuai standar, dengan penuh semangat dan berpartisipasi dalam perbaikan pelaksanaan pekerjaan sehingga menghasilkan lulusan dan/atau jasa pendidikan yang sesuai atau melebihi kebutuhan pihak yang berkepentingan. ${ }^{2}$

Menurut konteks pendidikan, pengertian mutu adalah input, proses, dan output pendidikan. ${ }^{3}$ Perkembangan teknologi informasi yang mampu mengolah, mengemas, dan menampilkan, serta menyebarkan informasi pembelajaran baik secara audio, visual, audiovisual bahkan multimedia, dewasa ini sangat mampu mewujudkan apa yang disebut virtual learning. ${ }^{4}$ Secara umum masalah yang dihadapi sekolah antara lain: administrasi sekolah yang belum dibenahi dengan baik, team working sekolah yang lemah yaitu sebagian pejabat sekolah sulit berkoordinasi dengan para guru dan personal lainnya dalam melaksanakan strategi sekolah, kurangnya kearsipan sekolah. Sarana dan prasarana pendidikan merupakan salah satu sumber daya yang penting dalam menunjang proses pembelajaran di sekolah. Keberhasilan program pendidkan di sekolah sangat dipengaruhi oleh kondisi sarana dan prasarana pendidikan yang dimiliki sekolah dan oleh optimalisasi pengelolaan dan pemanfaatannya. ${ }^{5}$ Adapun Komponenkomponen manajemen sekolah, yaitu: 1. Manajemen kurikulum dan program pengajaran 2. Manajemen tenaga kependidikan, manajemen kesiswaan,

\footnotetext{
${ }^{1}$ Ridwan Abdullah Sani \& Isda Pramuniarti, Penjaminan Mutu Sekolah, h. 3.

${ }^{2}$ Ridwan Abdullah Sani \& Isda Pramuniarti, Penjaminan Mutu Sekolah, h. 7.

${ }^{3}$ Nanang Hanafiah dan Cucu Suhana, Konsep Strategi Pembelajaran, h. 83-84.

${ }^{4}$ Deni Darmawan, Inovasi Pendidikan Pendekatan Praktik Teknologi Multimedia dan Pembelajaran Online (Cet. I; Bandung: PT Remaja Rosdakarya, 2012), h. 41.

${ }^{5}$ Matin dan Nurhattati Fuad, Manajemen Sarana dan Prasarana Pendidikan (Cet. I; Jakarta: Rajagrafindo Persada, 2016), h. 1.
} 
manajemen keuangan dan pembiayaan, manajemen sarana dan prasarana, manajemen hubungan sekolah dengan masyarakat, manajemen layanan khusus. ${ }^{6}$

Perkembangan teknologi informasi dan komunikasi melaju begitu cepat, merambah ke semua sektor kehidupan. Bahkan perekmbangannya diperkirakan lebih pesat dari perkiraan semula. Kita masih ingat, tiga hingga empat tahun yang laluteknologi informasi dan komunikasi seperti, komputer dan telepon selulerberbasis web, masih terbilang barang yang mahal dan hanya dimiliki orangorang tertentu saja.

Adanya perkembangan TIK yang menjadi jembatan ilmu, Salah satu peran TIK di era globalisasi ini adalah sebagai media informasi, misalnya internet. Peserta dapat mengeksplorasi informasi yang ada di seluruh dunia dengan lebih efisien dan efektif hanya dengan mengakses internet. Selain peran TIK sebagai media informasi, perkembangan TIK dapat pula dimanfaatkan peserta didik sebagai media komunikasi.

Mutu pendidikan harus diupayakan untuk mencapai kemajuan yang dilandasi oleh suatu perubahan terencana. Peningkatan mutu pendidkan diperoleh melalui dua strategi, yaitu peningkatan mutu pendidikan yang berorientasi akademis untuk memberi dasar minimal dalam perjalanan yang harus ditempuh mencapai mutu pendidikan yang dipersyaratkan oleh tuntutan zaman dan peningkatan mutu pendidikan yang berorientasi pada keterampilan hidup yang esensial yang dicakupi oleh pendidikan yang berlandasan luas, nyata dan bermakna. 7 Dalam kenyataannya, konsepsi tentang mutu masih tetap bergerak dalam bentukbentuknya yang masih bersifat retorikal. Artinya, mutu pendidikan masih bergerak dari gagasan yang satu kegagasan yang lain dan belum diterjemahkan secara tepat ke dalam ukuran dan tindakan yang lebih nyata. ${ }^{8}$

Masalah mutu pendidikan merupakan salah satu masalah nasional yang dihadapi dalam sistem pendidikan dan berbagai usaha dan program telah dikembangkan dalam rangka peningkatan mutu pendidikan, karena masalah mutu pendidikan merupakan suatu masalah yang sangat penting walaupun program peningkatan mutu pendidikan selama enam pelita secara terus-menerus selalu dilaksanakan, namun mutu pendidikan yang dicapai masih belum memuaskan, karena itu, perlu ditinjau bagaimana konseptual mutu pendidikan dilihat dari dua segi yakni segi normatif dan segi deskriptif. ${ }^{9}$

${ }^{6}$ E. Mulyasa, Manajemen Berbasis Sekolah Konsep Strategi dan Implementasi (Cet. 13; Bandung: PT. Remaja Rosda Karya, 2011), h. 41-50.

${ }^{7}$ Syaiful Sagala, Manajemen Strategik Dalam Peningkatan Mutu Pendidikan (Cet. V; Bandung: Alfabeta, 2011), h. 170.

${ }^{8}$ Syarifuddin Ondeng, Menyorot Lembaga Pendidikan Islam Era Global Studi Kritis Terhadap Manajemen Madrasah Di Era Informasi Dan Komunikasi (Cet. I; Makassar: Alauddin University Press, 2014), h. 205.

${ }^{9}$ Syarifuddin Ondeng, Menyorot Lembaga Pendidikan Islam Era Global Studi Kritis Terhadap Manajemen Madrasah di Era Informasi dan Komunikasi, h.205. 
Upaya dalam peningkatan mutu perlu dibangun sumber daya manusia yang profesional dan handal sesuai dengan kompetensi keilmuannya masing-masing sehingga dapat menjadi kekuatan besar dalam menghadapi realitas yang kompetitif dimasa yang akan datang. Profesional ini adalah sebuah istilah yang erat kaitannya dengan persiapan sumber daya manusia memasuki abad dua puluh satu yang penuh dengan dinamika problematika krusial. Ada yang menekankan profesionalisme kepada penguasaan beserta kiat-kiat dalam penerapannya dan ada pula yang menekankan kepada kemampuan manajemen. ${ }^{10}$

Berbagai pengamatan ternyata ada tiga hal pokok yang menyebabkan rendahnya mutu pendidikan yaitu: (1) kebijakan dan penyelenggaraan pendidikan nasional hanya memusatkan pada output pendidikan, padahal proses pendidikan sangat menentukan output pendidikan, (2) penyelenggaraan pendidikan nasional dilakukan secara birokratik-sentralistik sehingga menempatkan sekolah sebagai penyelenggara pendidikan sangat tergantung pada keputusan birokrasi pusat yang kadang-kadang tidak sesuai dengan kondisi sekolah setempat; sekolah kehilangan kemandirian, motivasi, inisiatif, dan kreativitas untuk meningkatkan mutu sekolahnya, (3) peran serta masyarakat khususnya orang tua siswa dalam penyelenggaraan pendidikan selama ini sangat minim. ${ }^{11}$

Dalam penelitian ini, masalah yang akan diteliti dirumuskan sebagai berikut:

1. Bagaimana kondisi objektif kompetensi manajerial kepala sekolah SMA Negeri 21 Makassar?

2. Bagaimana kemampuannya dalam aplikasi teknologi informasi dan komunikasi SMA Negeri 21 Makassar?

3. Bagaimana mutu pengelolaan SMA Negeri 21 Makassar?

4. Apakah terdapat hubungan kompetensi manajerial kepala sekolah dengan mutu pengelolaan SMA Negeri 21 Makassar?

5. Apakah terdapat hubungan aplikasi teknologi informasi dan komunikasi dengan mutu pengelolaan SMA Negeri 21 Makassar?

6. Apakah terdapat hubungan antara kompetensi manajerial kepala sekolah dan aplikasi TIK secara bersama-sama dengan mutu pengelolaan SMA Negeri 21 Makassar?

\section{KAIIAN PUSTAKA}

\section{Pengertian Kompetensi Manajerial Kepala Sekolah}

Kompetensi manajerial adalah kemampuan kepala sekolah dalam mengorganisasi dan mengembangkan sumber daya sekolah untuk menciptakan lingkungan belajar yang efektif dan efisien. Kompetensi merupakan salah satu

\footnotetext{
${ }^{10}$ Syarifuddin Ondeng, Menyorot Lembaga Pendidikan Islam Era Global Studi Kritis Terhadap Manajemen Madrasah di Era Informasi dan Komunikasi, h.209.

${ }^{11}$ Mulyono, Manajemen Administrasi \& Organisasi Pendidikan (Cet. I; Yogyakarta: Ar-Ruzz Media, 2009), h. 153-163.
} 
faktor penentu keberhasilan suatu profesi atau pekerjaan. Kompetensi adalah seperangkat pengetahuan, keterampilan, dan perilaku yang harus dimiliki, dihayati, dan oleh guru dalam melaksanakan tugas keprofesionalan. ${ }^{12}$

Kepala sekolah dapat diartikan sebagai gambaran tentang apa yang seharusnya dapat dilakukan seorang kepala sekolah dalam melaksanakan pekerjaannya, baik berupa kegiatan, berperilaku maupun hasil yang dapat ditunjukkan. ${ }^{13}$

Penulis mengartikan bahwa kompetensi manajerial kepala sekolah dan kompetensi seorang guru sangatlah penting untuk dimiliki oleh seorang kepala sekolah dan juga seorang guru. Kepala sekolah dan guru mempunyai peran yang begitu besar terhadap dunia pendidikan yaitu untuk mencerdaskan anak bangsa yang sesuai dengan tujuan pendidikan nasional. ${ }^{14}$

\section{Kemampuannya dalam Aplikasi Teknologi Informasi dan Komunikasi}

Teknologi informasi (TI) dilihat dari kata penyusunnya adalah teknologi dan informasi. Kata teknologi bermakna pengembangan dan penerapan berbagai peralatan atau sistem untuk menyelesaikan persoalan-persoalan yang dihadapi oleh manusia dalam kehidupan sehari-hari, kata teknologi berdekatan artinya denga istilah tatacara, informasi adalah data yang diproses kedalam bentuk yang lebih berati bagi penerima dan berguna dalam pengambilan keputusan, sekarang atau untuk masa yang akan datang. ${ }^{15}$

Teknologi informasi adalah sarana prasarana, sistem dan metode untuk perolehan, pengiriman, penerimaan, pengolahan dan penafsiran, penyimpanan, pengorganisasian dan penggunaan data yang bermakna. Teknologi informasi juga dapat dikatakan suatu teknologi yang digunakan untuk mengolah data, termasuk memproses, mendapatkan, menyusun, menyimpan, memanipulasi data daam berbagai cara untuk menghasilkan informasi yang berkualitas, yaitu informasi yang relevan, akurat dan tepat waktu, yang digunakan untuk keperluan pribadi pendidikan, bisnis, dan pemerintahan dan merupakan informasi yang strategis untuk pengambilan keputusan. ${ }^{16}$ Teknologi komunikasi adalah alat yang membawa pesan dari seorang individu ke individu lainnya. Selanjutnya, media juga dipandang sebagai bentuk-bentuk komunikasi massa yang melibatkan sistem simbol dan

\footnotetext{
${ }^{12}$ Kamsinah, Tugas dan Tanggung Jawab Guru dalam Pendidikan, h. 61.

${ }^{13}$ Ahmad Susanto, Konsep, Strategi dan Implementasi Manajemen Peningkatan Kinerja Guru, h. $17-18$.

${ }^{14}$ Nanang Fattah, Konsep Manajemen Berbasis Sekolah (MBS) dan Dewan Sekolah (Cet.I; Bandung: Pustaka Bani Quraisy, 2004), hal. 125-126. 2001), h. 45.

${ }^{15}$ Murhada dan Yo Ceng Giap, Pengantar Teknologi Informasi (Jakarta: Mitra wacana Media,

${ }^{16}$ Muhammad Ramli, Manajemen Pelayanan Publik Berbasis Kemanusiaan (Cet. III; Makassar: Alauddin Univerity Press, 2015), h. 172.
} 
peralatan produksi dan distribusi. ${ }^{17}$ Media adalah alat komunikasi yang dapat digunakan untuk membawa pesan dari pemberi kepada penerima pesan. ${ }^{18}$

Aplikasi Teknologi, Informasi dan Komunikasi adalah Internet sebagai sumber informasi tentang hal apapun tentu akan sangat membantu kehidupan masyarakat. Bagi mereka yang bekerja di bidang pendidikan, bidang literasi, atau bidang kesenian, bisa mencari berbagai informasi dari internet. Teknologi informasi adalah teknologi yang mampu membantu manusia untuk melakukan pekerjaan mereka. Teknologi informasi (information technology) merupakan bahasa latin "texere" atau yang berarti membangun. Teknologi sebenarnya memilki 2 (dua) aspek penting, yaitu hardware (perangkat keras) dans software (perangkat lunak). Teknologi informasi dapat didefenisikan secara sederhana sebagai suatu teknologi yang digunakan dalam pegolahan Sistem informasi. Namun dalam arti luas, teknologi informasi adalah suatu konsep yang meliputi hardware, software, proses operasional dan manajemen sistem informasi, teknologi jaringan, dan peralatan telekomunikasi lainnya, serta keahlian yang diperlukan untuk mengalokasikan produk dan peralatan tersebut dengan tujuan memproduksi informasi, melakukan pengembangan, manajemen dan pengawasan Sistem informasi. ${ }^{19}$

Teknologi informasi dan komunikasi adalah medium interaktif yang digunakan untuk berkomunikasi jarak jauh dalam rangka tukar-menukar informasi (media pengirim dan penerima pesan jarak jauh). ${ }^{20}$ Pengertian lain teknologi informasi dan komunikasi, yaitu perangkat teknologi yang memfasilitasi penggunaannya dengan berbagai kemudahan dalam mengakses informasi yang dibutuhkan, baik itu informasi yang disajikan dalam bentuk suara, tulisan, visual maupun dalam bentuk simbol, lambang informasi-informasi lainnya. ${ }^{21}$

Program aplikasi adalah program yang ditulis/dibuat untuk melaksanakan tugas khusus dari pengguna. 22 Teknologi informasi, dan komunikasi adalah berbagai aspek yang melibatkan teknologi, rekayasa dan teknik pengelolaan yang digunakan dalam pengendalian dan pemrosesan informasi serta penggunaannya, komputer dan hubungan mesin (komputer) dan manusia, dan hal yang berkaitan dengan sosial, ekonomi dan kebudayaan. Arti Teknologi Informasi dalam dunia pendidikan seharusnya berarti tersedianya saluran atau sarana yang dapat diapakai untuk menyiarkan program pendidikan. Di dunia pendidikan, banyak

\footnotetext{
${ }^{17}$ Safei, Teknologi Pembelajaran Pengertian, Pengembangan dan Aplikasinya (Cet. I; Makassar Alauddin University Press, 2013), h. 13.

${ }^{18}$ Safei, Teknologi Pembelajaran Pengertian, Pengembangan dan Aplikasinya, h.13-14.

${ }^{19}$ Abdul Kadir, Pengenalan Sistem Informasi (Yogyakarta: ANDI 2003), h. 33.

${ }^{20}$ Dewi Salma Prawiradilaga, Diana Ariani dan Hilman Handoko, Mozaik Teknologi Pendidikan e-learning (Cet. I: Jakarta: Kencana, 2013), h. 16.

${ }^{21}$ Dewi Salma Prawiradilaga, Diana Ariani dan Hilman Handoko, Mozaik Teknologi Pendidikan e-learning (Cet. I: Jakarta: Kencana, 2013), h. 26.

${ }^{22}$ George M. Scott, Prinsip-Prinsip Sistem Informasi Manajemen (Cet. VII; Jakarta: PT RajaGrafindo Persada, 2002), h. 219.
} 
sekali lembaga pendidikan yang telah berhasil mengembangkan Teknologi Informasi dan Komunikasi dalam mendukung proses pembelajarannya.

\section{Mutu Pengelolaan}

Pengertian mutu pendidikan mengandung makna yang berlainan. Namun perlu ada suatu defenisi operasional sebagai suatu pedoman dalam pengelolaan pendidikan untuk sampai pada pengertian mutu pendidikan. Menurut kamus besar bahasa Indonesia: "mutu adalah ukuran baik buruk suatu benda, keadaan, taraf, atau derajat (kepandaian, kecerdasan dan sebagainya)."23

Mutu ditentukan berdasarkan pertimbangan (kriteria) intrinsik dan ekstrinsik berdasarkan kriteria intrinsik, mutu pendidikan merupakan produk pendidikan yakni "manusia yang terdidik" sesuai dnegan standar ideal. Berdasarkan kriteria ekstrinsik, pendidikan merupakan instrument untuk mendidik" tenaga kerja" yang terlatih dalam artian deskriptif, mutu ditentukan berdasarkan keadaan senyatanya, misalnya hasil tes prestasi belajar. ${ }^{24}$

Peningkatan mutu pendidikan di sekolah perlu didukung kemampuan manajerial kepala sekolah. Sekolah perlu berkembang maju dari tahun ke tahun. Karena itu hubungn baik antara guru perlu diciptakan agar terjalin iklim dan suasana kerja yang kondusif dan menyenangkan. ${ }^{25}$ Demikian halnya penataan penampilan fisik dan manajemen sekolah perlu dibina agar sekolah menjadi lingkungan pendidikan yang dapat menumbuhkan kreativitas, disiplin, dan semangat belajar peserta didik. ${ }^{26}$

\section{HASIL PENELITIAN DAN PEMBAHASAN}

\section{Hasil Penelitian}

\section{- Analisis Deskriptif}

\section{Kategorisasi Kompetensi Manajerial Kepala Sekolah}

Adapun gambaran skor hasil kompetensi manajerial kepala sekolah SMA Negeri 21 Makassar menunjukkan bahwa nilai minimum adalah 15, nilai maksimumnya 43 dan rata-ratanya adalah 30,63 dengan standar deviasi 8,170 dari 40 jumlah responden.

Sementara pada kategorisasi menunjukkan bahwa ada 26 responden menyatakan sedang, 2 reponden menyatakan rendah dan 12 responden menyatakan tinggi mengenai kompetensi manajerial kepala sekolah di SMA Negeri 21 Makassar.

\section{Kategorisasi Kemampuannya Dalam Aplikasi Teknologi Informasi dan Komunikasi}

\footnotetext{
${ }^{23}$ Tim Penyusun, Kamus Besar Bahasa Indonesia (Cet. III; Jakarta, 2007), h.31.

${ }^{24}$ Oemar Hamalik, Evaluasi Kurikulum (Cet. I; Bandung: Remaja Rosdakarya, 1990), h.33.

${ }^{25}$ E Mulyasa, Manajemen Berbasis Sekolah, Konsep, Strategi dan Implikasi (Cet.VII: Bandung: Remaja Rosdakarya, 2004), h. 57.

${ }^{26}$ E Mulyasa, Manajemen Berbasis Sekolah, Konsep, Strategi dan Implikasi, h. 57.
} 
Adapun gambaran skor hasil kompetensi manajerial kepala sekolah SMA Negeri 21 Makassar menunjukkan bahwa nilai minimum 3, nilai maksimum 8 dan rata-ratanya adalah 6 dengan standar deviasi 1,240 dari 40 jumlah responden.

Sementara pada kategorisasi menunjukkan bahwa ada 23 responden menyatakan sedang, 1 reponden menyatakan rendah dan 16 responden menyatakan tinggi mengenai kemampuannya dalam aplikasi Teknologi informasi dan komunikasi di SMA Negeri 21 Makassar.

\section{Kategorisasi Mutu Pengelolaan}

Adapun gambaran skor hasil Mutu Pengelolaan SMA Negeri 21 Makassar terlihat bahwa nilai minimum 8, nilai maksimum 20 dan rata-ratanya adalah 14,30 dengan standar deviasi 3,131 dari 40 jumlah responden.

Sementara pada kategorisasi menunjukkan bahwa ada 29 responden menyatakan sedang, 1 reponden menyatakan rendah dan 10 responden menyatakan tinggi mengenai mutu pengelolaan di SMA Negeri 21 Makassar.

\section{- Analisis Inferensial}

\section{Kategorisasi Kompetensi Manajerial Kepala Sekolah}

Hasil pengujian normalitas dengan menggunakan metode One Sample Kolmogorov-Smirnov

Hipotesis:

$\mathrm{H}_{0}$ : Sampel berasal dari populasi berdistribusi normal

$\mathrm{H}_{1}$ : Sampel berasal dari populasi berdistribusi tidak normal

Kriteria pengujian yang digunakan adalah Jika nilai sig. ( $p$-value) > 0,05 maka $\mathrm{H}_{0}$ diterima. Berdasarkan hasil outpust SPSS didapatkan bahwa: Variabel Kompetensi Pedagogik, nilai sig. ( $p$-value) sebesar 0,648 >0.05, maka $\mathrm{H}_{0}$ diterima. Artinya sampel variable Kemampuan Manajerial Kepala Sekolah berasal dari populasi normal.

\section{Kategorisasi Kemampuannya Dalam Aplikasi Teknologi Informasi dan Komunikasi}

Hasil pengujian normalitas dengan menggunakan metode One Sample Kolmogorov-Smirnov

Hipotesis:

$\mathrm{H}_{0}$ : Sampel berasal dari populasi berdistribusi normal

$\mathrm{H}_{1}$ : Sampel berasal dari populasi berdistribusi tidak normal

Kriteria pengujian yang digunakan adalah Jika nilai sig. ( $p$-value) $>0,05$ maka $\mathrm{H}_{0}$ diterima. Berdasarkan hasil outpust SPSS tampak bahwa: Variabel Kompetensi Pedagogik, nilai sig. ( $p$-value) sebesar 0,082 > 0.05, maka $\mathrm{H}_{0}$ diterima. Artinya sampel variable Kemampuan Aplikasi TIK berasal dari populasi normal.

\section{Kategorisasi Mutu Pengelolaan}

Hasil pengujian normalitas dengan menggunakan metode One Sample Kolmogorov-Smirnov 
Hipotesis:

$\mathrm{H}_{0}$ : Sampel berasal dari populasi berdistribusi normal

$\mathrm{H}_{1}$ : Sampel berasal dari populasi berdistribusi tidak normal

Kriteria pengujian yang digunakan adalah Jika nilai sig. ( $p$-value) $>0,05$ maka $\mathrm{H}_{0}$ diterima. Berdasarkan hasil outpust SPSS tampak bahwa: Variabel Kompetensi Pedagogik, nilai sig. ( $p$-value) sebesar 0,685 > 0.05, maka $\mathrm{H}_{0}$ diterima. Artinya sampel variable Mutu Pengelolaan Sekolah berasal dari populasi normal.

\section{- Analisis Korelasi Pearson}

\section{Hubungan antara Kompetensi Manajerial Kepala Sekolah dengan Mutu Pengelolaan}

Analisis korelasi pearson adalah analisis untuk mengukur keeratan hubungan secara linier antara dua variabel yang mempunyai distribusi data normal.

Berdasarkan hasil penghitungan dapat dijelaskan bahwa korelasi antara kompetensi manajerial kepala sekolah dengan mutu pengelolaan didapat nilai koefisien sebesar 0,187. Karena signifikansi > 0,05 maka $\mathrm{H}_{0}$ ditolak, maka dapat disimpulkan bahwa antara kompetensi manajerial kepala sekolah dengan mutu pengelolaan memiliki hubungan yang rendah.

\section{Hubungan antara Kemampuannya dalam Aplikasi Teknologi Informasi dan Komunikasi dengan MutuPengelolaan}

Analisis korelasi pearson adalah analisis untuk mengukur keeratan hubungan secara linier antara dua variabel yang mempunyai distribusi data normal.

Berdasarkan hasil penghitungan, dapat dijelaskan bahwa korelasi antara kemampuannya dalam aplikasi teknologi informasi dan komunikasi dengan mutu pengelolaan didapat nilai koefisien sebesar 0,627. Karena signifikansi $>0,05$ maka $\mathrm{H}_{0}$ ditolak, maka dapat disimpulkan bahwa antara kemampuannya dalam aplikasi teknologi informasi dan komunikasi dengan mutu pengelolaan memiliki hubungan yang erat.

\section{Hubungan antara Kompetensi Manajerial Kepala Sekolah dan Kemampaunnya dalam Aplikasi Teknologi Informasi dan Komunikasi dengan Mutu Pengelolaan}

Analisis korelasi pearson adalah analisis untuk mengukur keeratan hubungan secara linier antara dua variabel yang mempunyai distribusi data normal.

Berdasarkan hasil penghitungan, dapat dijelaskan bahwa korelasi antara kompetensi manajerial kepala sekolah dengan mutu pengelolaan didapat nilai koefisien sebesar 0,187. Karena signifikansi $>0,05$ maka $\mathrm{H}_{0}$ ditolak, maka dapat disimpulkan bahwa antara kompetensi manajerial kepala sekolah dengan mutu pengelolaan memiliki hubungan yang renda sedangkan korelasi antara kemampuannya dalam aplikasi teknologi informasi dan komunikasi dengan mutu pengelolaan didapat nilai koefisien sebesar 0,627. Karena signifikansi > 0,05 maka $\mathrm{H}_{0}$ ditolak, maka dapat disimpulkan bahwa antara kemampuannya dalam 
aplikasi teknologi informasi dan komunikasi dengan mutu pengelolaan memiliki hubungan yang erat. Jadi dapat disimpulkan bahwa hubungan antara kompetensi manajerial kepala sekolah dan kemampuannya dalam aplikasi teknologi informasi dan komunikasi dengan mutu pengelolaan SMA Negeri 21 Makassar memiliki hubungan yang erat.

\section{Pembahasan}

Berdasarkan hasil analisis dengan menggunakan statistik deskriptif dapat dikemukakan bahwa pada variabel kompetensi manajerial kepala sekolah terlihat nilai minimum adalah 15, nilai maksimum 43 dan rata-ratanya adalah 30,63 dengan standar deviasi 8,170 dari 40 jumlah responden. Dari tabel 3 di atas menunjukkan bahwa ada 26 responden menyatakan sedang, 2 reponden menyatakan rendah dan 12 responden menyatakan tinggi mengenai kompetensi manajerial kepala sekolah di SMA Negeri 21 Makassar. Hasil analisis variabel kemampuannya dalam aplikasi teknologi informasi dan komunikasi dapat dilihat dari tabel bahwa nilai minimum 3, nilai maksimum 8 dan rata-ratanya adalah 6 dengan standar deviasi 1,240 dari 40 jumlah responden. Dari tabel 6 di atas menunjukkan bahwa ada 23 responden menyatakan sedang, 1 reponden menyatakan rendah dan 16 responden menyatakan tinggi mengenai variabel kemampuannya dalam aplikasi Teknologi informasi dan komunikasi di SMA Negeri 21 Makassar. Dan hasil analisis deskriptif variabel mutu pengelolaan dapat dilihat bahwa nilai minimum adalah 8 , nilai maksimum 20 dan rata-ratanya adalah 14,30 dengan standar deviasi 3,131 dari 40 jumlah responden. Dari tabel 9 di atas menunjukkan bahwa ada 29 responden menyatakan sedang, 1 reponden menyatakan rendah dan 10 responden menyatakan tinggi mengenai mutu pengelolaan di SMA Negeri 21 Makassar.

Berdasarkan hasil pengujian satistik inferensial, Variabel Kompetensi Pedagogik, nilai sig. ( $p$-value) sebesar 0,648 > 0.05, maka $\mathrm{H}_{0}$ diterima. Variabel kemampuan dalam aplikasi TIK, nilai sig. ( $\mathrm{p}$-value) sebesar 0,082 >0.05, maka $\mathrm{H}_{0}$ diterima dan variabel mutu pengelolaan, nilai sig. ( $p$-value) sebesar 0,685 >0.05, maka $\mathrm{H}_{0}$ diterima. Artinya sampel variable kompetensi manajerial kepala sekolah, akemampuan dalam aplikasi TIK dan Mutu Pengelolaan Sekolah berasal dari populasi berdistribusi normal.

Berdasarkan uraian di atas, maka dapat disimpulkan bahwa kompetensi manajerial kepala sekolah dengan mutu pengelolaan mempunyai hubungan yang rendah dan variabel kemampuan dalam aplikasi TIK dengan mutu pengelolaan mempunyai hubungan yang sangat erat sesuai hasil analisis korelasi pearson product moment.

\section{KESIMPULAN DAN SARAN}

Berdasarkan hasil analisis data dan pembahasan, maka dapat disimpulkan bahwa: 
1. Kompetensi manajerial kepala sekolah di SMA Negeri 21 Makassar masih sangat rendah dan perlu ditingkatkan dengan berbagai bentuk pelatihan

2. Kemampuannya dalam aplikasi teknologi informasi dan komunikasi SMA Negeri 21 Makassar tergolong sudah tinggi

3. Mutu pengelolaan SMA Negeri 21 Makassar sudah baik karena ditunjang oleh kompetensi manajerial kepala sekolah dan penerapan aplikasi teknologi informasi dan komunikasi

4. Hubungan kompetensi manajerial kepala sekolah dengan mutu pengelolaan SMA Negeri 21 Makassar termasuk dalam kategori rendah.

5. Hubungan aplikasi teknologi informasi dan komunikasi dengan mutu pengelolaan SMA Negeri 21 Makassar tergolong sangat tinggi

6. Hubungan antara kompetensi manajerial kepala sekolah dan aplikasi TIK secara bersama-sama dengan mutu pengelolaan SMA Negeri 21 Makassar termasuk dalam kategori tinggi

Berdasarkan hasil penelitian salah satu hal yang menyebabkan kurang baiknya kompetensi manajerial kepala sekolah adaah kurang adanya keterampilan dalam mengelola sekolah, kurang mampu membuat perogram diakibatkan oleh krangnya keterampilan yang dimiliki oleh kepala sekolah. Oleh sebab itu, disarankan bagi kepala sekolah agar sering mengikuti pelatihan, berdiskusi dengan teman sejawat, berkunjung ke sekolah yang sudah bagus mutunya.

Penerapan aplikasi TIK sudah berada pada kategori baik penggunaannya, oleh karena itu perlu diarahkan kepada anak didik agar menggunakan dalam hal yang positif, dalam hal ini perlu pendampingan dari guru terutama guru TIK. Mutu pengelolaan sekolah akan meningkat apabila ditunjang oleh berbagai pihak terutama dalam penggunaan sarana dan prasarana yang memadai. Dengan demikian, semua hasil yang diharapkan oleh sekolah dapat tercapai karena dukungan dari berbagai pihak.

\section{DAFTAR PUSTAKA}

Darmawan, Deni. Inovasi Pendidikan Pendekatan Praktik Teknologi Multimedia dan Pembelajaran Online. Cet. I; Bandung: PT Remaja Rosdakarya, 2012.

Fattah, Nanang. Konsep Manajemen Berbasis Sekolah (MBS) dan Dewan Sekolah. Cet.l. Bandung: Pustaka Bani Quraisy, 2004.

Hamalik, Oemar. Proses Belajar-Mengajar. Jakarta: PT Bumi Aksara, 2006.

Hanafiah, Nanang dan Cucu Suhana. Konsep Strategi Pembelajaran. Cet. II; Bandung: Refika Aditama, 2010.

Mulyono. Manajemen Administrasi \& Organisasi Pendidikan. Cet. I; Yogyakarta: ArRuzz Media, 2009.

Kamsinah. Tugas dan Tanggung Jawab Guru dalam Pendidikan Islam. Cet. I; Makassar: Alauddin University Press, 2014. 
KURNIATI

Matin dan Nurhattati Fuad. Manajemen Sarana dan Prasarana Pendidikan (Cet. I; Jakarta: Rajagrafindo Persada, 2016.

Murhada dan Yo Ceng Giap. Pengantar Teknologi Informasi. Jakarta: Mitra Wacana Media, 2001.

Mulyasa, E. Manajemen Berbasis Sekolah Konsep Strategi dan Implementasi. Cet. 13; Bandung: PT Remaja RosdaKarya, 2011.

Ondeng, Syarifuddin. Menyorot Lembaga Pendidikan Islam Era Global Studi Kritis Terhadap Manajemen Madrasah Di Era Informasi Dan Komunikasi. Cet. I; Makassar: Alauddin University Press, 2014.

Prawiradilaga, Dewi Salma \& Diana Ariani. Mozaik Teknologi Pendidikan ELearning. Cet. I; Jakarta: Kencana Prenada MediaGroup, 2013.

Ramli, Muhammad. Manajemen Pelayanan Publik Berbasis Kemanusiaan. Cet. III; Makassar: Alauddin Univerity Press, 2015.

Sani, Ridwan Abdullah \& Isda Pramuniati, Penjaminan Mutu Sekolah. Cet. I; Jakarta: Bumi Aksara, 2015.

Sagala, Syaiful. Manajemen Strategik dalam Peningkatan Mutu Pendidikan. Cet. V; Bandung: Alfabeta, 2011.

Safei. Teknologi Pembelajaran Pengertian, Pengembangan dan Aplikasinya. Cet. I; Makassar: Alauddin University Press, 2013.

Susanto, Ahmad. Konsep, Strategi dan Implementasi Manajemen Peningkatan Kinerja Guru, 2016.

Scott, George M. Prinsip-Prinsip Sistem Informasi Manajemen. Cet. VII; Jakarta: PT Raja Grafindo Persada, 2002. 